\title{
Global Climate Change and the South African Flora: Past, Present and Future
}

The National Botanical Institute, Kirstenbosch, in conjunction with the University of Cape Town, Botany Department are undertaking the biodiversity component of the South African Country Study on Climate Change (SACSCC) project. The specific objective of the project is to provide future plant diversity scenarios given changes in climate, combined with UV-B flux and atmospheric $\mathrm{CO}_{2}$ changes. The question of biodiversity is highly relevant to South Africa, due to its extremely rich, unique flora with high levels of endemism. For example, the Cape Floral Kingdom (CFK) is the smallest floral kingdom in the world, covering approximately 90,000 square kilometers, with approximately 8,600 species of plants. Of these plants 5,800 are endemic to the CFK. Four fifths of the CFK is composed of the world famous Cape Fynbos vegetation (Fig. 14). This vegetation type is characterized by four growth forms: tall protea shrubs (proteoids); heath like shrubs (ericoids); reedlike plants (restioids); and bulbous herbs (geophytes). Adjacent to the Cape Floral Kingdom is the Succulent Karoo Biome, which is home to almost $60 \%$ of the world's succulent flora (Cowling and Richardson 1995). Assessing the effects of future global warming on the flora of South Africa is thus an important task in light of the high plant diversity in the region.

As part of this study, a database of all the paleobotanical information (predominantly

\section{PAGES Science and Biodiversity}

It is difficult to define any direct contribution from PAGES-style paleo-science to biodiversity issues, at least in relation to terrestrial ecosystems, The concept is only meaningful at the biological species (or 'lower') hierarchical level. Taxa tend to respond to environmental change rather individualistically and the level of taxonomic resolution we can achieve, using pollen analysis for example, is rarely adequate. At least we can contribute insight into past variations in physico-chemical conditions; perhaps also some indication of biotic responses from the recorded changes in distribution of a few, possibly 'indicative' taxa. The questions then are:

- if this is the most we can realistically do, is it useful in any discourse about the maintenance of future biodiversity?

- if we set out with 'biodiversity' as a priority issue, might we find ways of addressing it more effectively?

The article by Allsopp et al. illustrates the way in which the paleo-science dimensions are being considered within the context of one of the world's richest and most fascinating regions from the point of view of higher plant biodiversity. We hope to take up the issue with regard to aquatic biodiversity in a subsequent Newsletter.

Frank Oldfield pollen and charcoal remains) since the last glacial maximum (18k BP) available for South Africa is being compiled. Unfortunately, the paleobotanical legacy in this region is poor, unlike the northern hemisphere where conditions associated with glacier retreat have allowed good estimation of vegetation movement. We have recorded the taxa present at approximately 30 sites in South Africa at various times in the past. All the relevant literature on past plant (Family, Genus or Species level) occurrences is being collected. A database of all the identified plant occurrences in South Africa is being compiled. We are attempting to compile a complete list of similar projects which are being conducted (Prentice 1996, Partridge et al. in prep) such as the Biome 6000 project (Prentice 1996) which aims to product a global data set of past vegetation for 6,000 radiocarbon years ago, based on pollen and plant macrofossil records. Unlike the Biome 6000 project the information which we are assembling for the SACSCC project is only for South Africa. This information will allow us to assess past distributions of important taxa and vegetation groupings to provide estimates of rates of movement in the past. The database has been linked to a Geographical Information System (GIS) in order to provide a visual means of displaying the sites and taxa. Using this program an attempt will be made to determine the movement of taxa over the past 18,000 years.

As part of this project we will also be modelling the future movement of plant taxa in South Africa based on the climatic scenarios which have been provided for the country. This is a refinement of the one step distribution changes of previous work in South Africa (Rutherford et al. 1995 a \& b). The changes in dis-

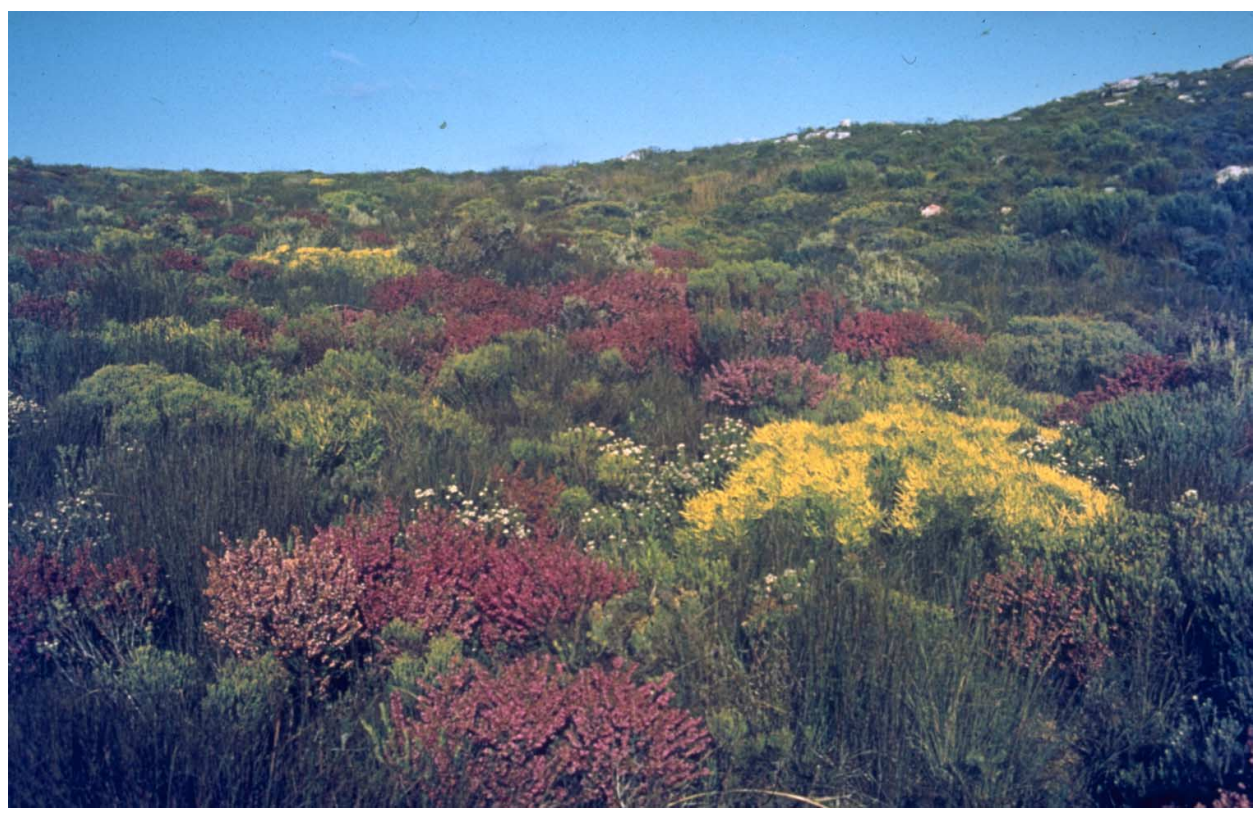

Fig. 14: Fynbos with Ericaceae and Proteaceae and Restionaceae (Photo: Percy Sergeant Memorial Collection, Janet Allsopp) tribution of vegetation types and some specific taxa at selected intervals of time over the next approximately 50 years will be mapped in an attempt to determine how terrestrial biodiversity will be affected by future climatic changes. This project is novel in South Africa, incorporating past vegetation changes with future changes in plant distribution and assessing the changes in biodiversity.

\section{J.C.N. Ausopp}

National Botanical Institute, Private Bag x7,

Claremont 7735, South Africa

allsopp@nbict.nbi.ac.za

\section{W.J. BOND}

Department of Botany, University of Cape Town, Rondebosch, South Africa

\section{G.F. Midgley and M.C. Rutherford}

National Botanical Institute, Claremont, South Africa

\section{References: \\ 1. Cowling, R.M. ANd Richardson, D.M. 1995 Fynbos, South Africa's unique floral kingdom. Fernwood Press. Singapore. \\ 2. PrentiCE, C. 1996. Biome 6000: progress and plants. IGBP Newsletter 27. \\ 3. Rutherford, M.C. et Al. 1995 A. Realised niche spaces and functional types: a framework for prediction of compositional change. Journal of Biogeography 22: 523-531}

4. RUtherford, M.C. et Al. 1995 B. Modelling survival of plant populations with differing mobility and sensitivity to climate change over real and simulated terrain types. In: Binning, P. et al. (eds). International Congress of Modelling and Simulations Proceedings. Vol 1 pp. 94-101. The Modelling and Simulations Society of Australia Inc., Canberra.

5. Jolly, D. ET AL. Biome reconstruction from pollen and plant macrofossil data for Africa and the Arabian Peninsula at 0 and $6 \mathrm{ka}$. In prep.

6. Partridge, T.C. et al. Synthetic reconstructions of southern African environments during the Last Glacial Maximum (21 - $18 \mathrm{kyr}$ ) and the Holocene altithermal (8 - $6 \mathrm{kyr})$. In prep. 